\title{
Performance Evaluating of IT Department using a Modified Fuzzy TOPSIS and BSC methodology (Case study: Tehran Province Gas Company)
}

\author{
Amir Manian \\ Associate Professor, Faculty of Management \\ University of Tehran, Tehran, Iran \\ Mohammad Reza Fathi (Corresponding author) \\ M.S. Candidate of Industrial Management \\ University of Tehran, Tehran, Iran \\ Email: reza.fathi@ut.ac.ir \\ Mohammad Karimi Zarchi \\ M.S. Candidate of Industrial Management \\ University of Tehran, Tehran, Iran \\ Asie Omidian \\ M.S. Candidate of business Management \\ University of Tehran, Tehran, Iran
}

Received: April 22, 2011 Accepted: May 3, 2011 doi:10.5296/jmr.v3i2.640

\begin{abstract}
This research has been conducted in Tehran province Gas Company which is a governmental company. The objective of this study is to construct an approach based on the modified fuzzy TOPSIS and balanced scorecard (BSC) for evaluating an IT department in Tehran Province Gas Company. The BSC concept is applied to define the hierarchy with four major perspectives (i.e. financial, customer, internal business process, and learning and growth), and performance indicators are selected for each perspective. A fuzzy TOPSIS approach is then proposed in order to tolerate vagueness and ambiguity of information. A fuzzy TOPSIS information system is finally constructed to facilitate the solving process. The results provide guidance to IT departments regarding strategies for improving department performance. The constructed information system is suggested to be a good tool for solving other multiple-criteria decision-making problems.
\end{abstract}

Keywords: Fuzzy TOPSIS; Balanced scorecard (BSC); Performance evaluation; Information technology (IT); Multicriteria. 


\section{Introduction}

Information technology (IT) involves computers, software and services, but good IT must synthesize these elements to achieve the goal of an organization. As a demand to collect, process, store, and disseminate information grows, the functions of IT department is becoming increasingly important. Although businesses invest huge amount of intellectual and financial capital in a range of communication and information technologies and services, the results of some surveys revealed that some companies have started to freeze IT budgets because there are insufficient evidence of a return from the investments and IT applications seem to be simply a black hole (Martinsons, Davison, and Tse, 1999). The reason behind is that it is difficult for managers to demonstrate tangible returns on the resources expended to plan, develop, implement and operate computer-based information system (IS). Some frequently asked questions by the organizations are whether the investment in IT/IS is really worthwhile, whether the implemented IT application is a success, and whether the IT department functions productively. The measurement of the value of IT and the evaluation of IS performance, thus, become of great importance to managers. Many methods and techniques have been suggested over the years to evaluate the investments in IT/IS or the performance of IT departments. However, well-known financial measures such as return on investment (ROI), internal rate of return (IRR), net present value (NPV) and payback period have been demonstrated to be inadequate (Abran \& Buglione, 2003). In the assessment of IT/IS investments or departments, it is critical to understand how IT/IS contribute to organizational and strategic goals, and evaluation methods that rely on financial measures alone are not suitable for IT applications. The balanced scorecard (BSC), a performance measurement framework that provides an integrated look at the business performance of a company by a set of both financial and non-financial measures, seems to be a good solution. However, conventional BSC does not consolidate these performance measures, and an incorporation of BSC and TOPSIS is an improvement. Since fuzziness and vagueness are common characteristics in many decision-making problems, a fuzzy TOPSIS and BSC method should be able to tolerate vagueness or ambiguity, and therefore, is proposed in this research.

The remainder of this paper is organized as follows. Section 2 briefly introduces the BSC. Section 3 reviews the incorporation of BSC with other methodologies and the application of the BSC in IT/IS field. In section 4, a modified fuzzy TOPSIS methodology is presented. In Section 5, the proposed methodology is applied to evaluate IT department. Finally, conclusions are given in the last section.

\section{The balanced scorecard (BSC)}

Focusing exclusively on traditional financial accounting measures, such as return on investment and payback period, has implications, and has been criticized as the root cause for many problems in industries (Hafeez, Zhang, \& Malak, 2002). As managers stress on short-term financial performance metrics, they have a tendency to trade off actions, such as new product development, process improvements, human resource development, information technology and customer and market development that can bring in long-term benefits, for 
current profitability, and this limits the investments with future growth opportunities (Banker, Chang, Janakiraman, \& Konstans, 2004). Such actions of managers are a consequence of poorly designed performance measurement systems that only focus on short-term financial performance. In the attempt to solve the problem by supplementing financial measures with additional measures that can help evaluate the long-term performance of a firm, Kaplan and Norton introduced the BSC, a performance measurement framework that provides an integrated look at the business performance of a company by a set of measures, which includes both financial and non-financial metrics ([Kaplan and Norton, 1992], [Kaplan and Norton, 1993] and [Kaplan and Norton, 1996a]). The name of BSC is with the intent to keep score of a set of measures that maintain a balance "between short- and long-term objectives, between financial and non-financial measures, between lagging and leading indicators, and between internal and external performance perspectives" (Kaplan \& Norton, 1996b). Of the BSC's four performance perspectives, one is a traditional financial performance group of items, and the other three involve non-financial performance measurement indexes: customer, internal business process, and learning and growth. The four perspectives are explained briefly as follows (Kaplan \& Norton, 1996b):

- Financial: This perspective typically contains the traditional financial performance measures, which are usually related to profitability. The measurement criteria are usually profit, cash flow, ROI, return on invested capital (ROIC), and economic value added (EVA).

- Customer: Customers are the source of business profits; hence, satisfying customer needs is the objective pursued by companies. In this perspective, management determines the expected target customers and market segments for operational units and monitors the performance of operational units in these target segments. Some examples of the core or genetic measures are customer satisfaction, customer retention, new customer acquisition, market position and market share in targeted segments.

- Internal business process: The objective of this perspective is to satisfy shareholders and customers by excelling at some business processes that have the greatest impact. In determining the objectives and measures, the first step should be corporate value-chain analysis. An old operating process should be adjusted to realize the financial and customer dimension objectives. A complete internal business-process value chain that can meet current and future needs should then be constructed. A common enterprise internal value chain consists of three main business processes: innovation, operation and after-sale services.

- Learning and growth: The primary objective of this perspective is to provide the infrastructure for achieving the objectives of the other three perspectives and for creating long-term growth and improvement through people, systems and organizational procedures. This perspective stresses employee performance measurement, such as employee satisfaction, continuity, training and skills, since employee growth is an intangible asset to enterprises that will contribute to business growth. In the other three dimensions, there is often a gap between the actual and target human, system and procedure capabilities. Through learning and growth, enterprises can decrease this gap. The criteria include turnover rate of workers, expenditures on new technologies, expenses on training, and lead time for introducing innovation to a 
market.

The BSC objectives and measures are determined by organizational visions and strategies and are intended to measure organizational performance using the four perspectives. Kaplan and Norton (1996b) stress the importance of adhering to three principles in developing BSC: maintaining cause-and-effect relationships, comprising sufficient performance drivers and keeping a linkage to financial measures. They also emphasize that the BSC is only a template and must be customized for the specific elements of an organization or industry. Depending on the sector in which a business operates and on the strategy chosen, the number of perspectives can be enlarged, or one perspective can be replaced by the other. In addition, the BSC concept can be applied to measure, evaluate and guide activities in specific functional areas of a business, and even at the individual project level (Martinsons et al., 1999).

Since its introduction, BSC has been adopted by many companies as a foundation for strategic management system. It has helped managers to align their businesses to new strategies towards growth opportunities based on more customized, value-adding products and services and away from simply cost reduction (Martinsons et al., 1999). BSC software programs have even been developed to extract data from computer-based information system (IS) to obtain required performance indices.

\section{The incorporation of BSC with other methodologies and the application of BSC in IT/IS field}

Some recent researches related to the combination of the BSC and other methodologies are reviewed here. Banker et al. (2004) do a BSC analysis of performance metrics in the US telecommunications industry. Four performance metrics are used to fit the template of four perspectives of the BSC, i.e., return on assets (ROA), number of access lines per employee, percentage of digital access lines and percentage of business access lines for the financial, internal process, innovation and learning, and customer perspective, respectively. A data envelopment analysis (DEA) model is then constructed to investigate the frontier relationship between the financial performance metric (ROA) and three non-financial performance metrics. The results show that two of the three non-financial metrics do not require any tradeoff with the financial metric, while the third non-financial metric (percentage of business access lines) does require tradeoffs with the financial metric and must be included properly in the performance measurement and evaluation system. Ravi, Shankar, and Tiwari (2005) analyze alternatives in reverse logistics for end-of-life computers by an analytic network process (ANP) and BSC approach. The ANP structures the problem related to options in reverse logistics in a hierarchical form, and the dimensions of reverse logistics are taken from four perspectives derived from the BSC approach. With the ANP, the interdependencies among criteria, sub-criteria and determinants for the options can be considered. With the BSC, financial and non-financial, tangible and intangible, internal and external factors can be linked. As a result, a combination of BSC and ANP-based approach provides a more realistic, accurate and holistic framework for the problem. 


\section{Al Macrothink}

Journal of management research

ISSN 1941-899X

2011, Vol. 3, No. 2: E10

The BSC has been utilized extensively in various fields, so as in the IT/IS field. Kaplan and Norton (1992) use an IT-company as an example to illustrate the use of the BSC by establishing a BSC framework, selecting a number of metrics, and setting a number of targets for top management. Willcocks and Lester (1994) tailor the BSC framework to the specific needs of IT investment evaluation in a major European ferry company. (Martinsons, 1992) and (Martinsons et al., 1999) suggest the use of BSC to help managers evaluate IT investments and the performance of IS organizations, in a holistic manner. Abran and Buglione (2003) argue that the traditional BSC cannot integrate the perspectives automatically into a consolidated view and thus the frameworks do not tackle the contribution of each goal to the whole BSC. A multidimensional performance model for consolidating BSCs for information and communication technology organizations is proposed by using the quality factor + economic, social and technical dimensions (QEST) for the BSC. Milis and Mercken (2004) review the traditional capital investment appraisal techniques, such as payback period (PP), accounting rate of return (ARR)/ROI, IRR and NPV, for information and communication technology projects and discuss the drawbacks of these methods. A multi-layer evaluation process that uses a mixture of the BSC and multi-layer evaluation is proposed by eliminating or diminishing the weaknesses of the conventional techniques.

Even though the BSC framework tackles performance at several levels, from the organizational level to the small business unit, and to the individual level, there are some disadvantages and pitfalls in the application. First of all, there are no generic measures or perspectives that fit all organizations or all business units (Milis \& Mercken, 2004). The expertise and background of the users, therefore, are very valuable in setting the framework. Secondly, with a variety of quantitative indicators, the BSC does not consolidate these performance values, neither for the individual perspectives nor for their consolidation (Abran $\&$ Buglione, 2003). The BSC does not provide a technique to estimate quantitatively how much each perspective contributes, either in relative or in absolute terms, nor does it estimate the relative importance of indicators under the same perspective (Abran \& Buglione, 2003).

\section{A modified TOPSIS methodology}

In the following, some basic definitions and notations of fuzzy sets are given briefly:

A fuzzy number is a fuzzy subset in the universe of discourse $X$ that is both convex and normal. Fig. 1 shows a fuzzy number $\tilde{\tau}$ of the universe of discourse $\mathrm{X}$ which is both convex and normal.

The $\alpha$-cut of a fuzzy number $\tilde{\tau}$ is defined

$\tilde{\tau}^{a}=x_{i}: \mu_{i}\left(x_{i}\right) \geq \alpha \quad x_{i} \quad x$

$\tilde{\mathrm{\tau}}$ is a non-empty bounded closed interval contained in $\mathrm{X}$ and it can be denoted by

$\widetilde{\tau}^{a}=\left[\tau_{f}^{\tilde{\sigma}}, \tau_{\mathrm{m}}^{\tilde{\alpha}}\right]$, $\tau_{l}^{a}$ and $\tau_{m}^{a}$ are the lower and upper bounds of the closed interval, respectively. Fig. 2 shows a fuzzy number $\approx$ with $\alpha$-cuts, where 


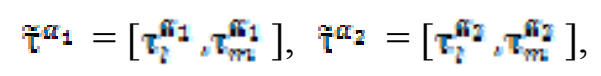

From Fig. 2, we can see that if alpha $2 \geq \alpha_{1}$, then $\tau_{i}^{\alpha_{2}} \geq \tau_{l}^{\alpha_{2}}$ and $\tau_{\mathrm{r}}^{\alpha_{2}} \geq \tau_{\mathrm{m}}^{\alpha_{2}}$ (Chen, 2000).

A triangular fuzzy number (TFN) $\tilde{\tau}$ can be defined by a triplet $\left(\tau_{1}, \tau_{2}, \tau_{3}\right)$ shown in Fig. 3 .

The membership function $\mu_{\tilde{\tau}}\left(\mathrm{x}_{\mathrm{i}}\right)$ is defined as in Eq. (3):

$$
\mu_{i}\left(x_{i}\right)=\left\{\begin{array}{ccc}
0 & x_{1} \leq & \tau_{1} \\
\frac{\pi-\tau_{1}}{\tau_{2}-\tau_{1}} & \tau_{1} \leq & \tau_{\mathrm{z}} \\
\frac{w-\tau_{3}}{\tau_{2}-\tau_{3}} & \tau_{2} \leq & \tau_{8} \\
0 & x \geq & \tau_{\mathbb{8}}
\end{array}\right.
$$

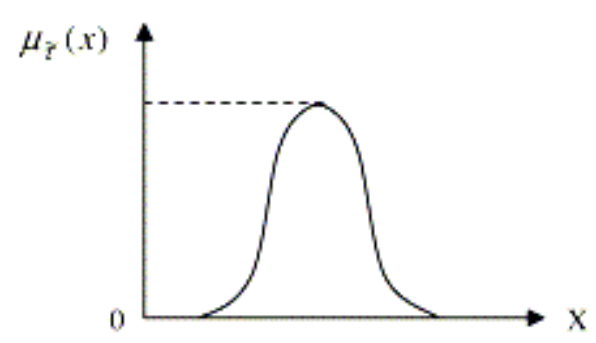

Figure 1. A fuzzy number $\tilde{\tau}$

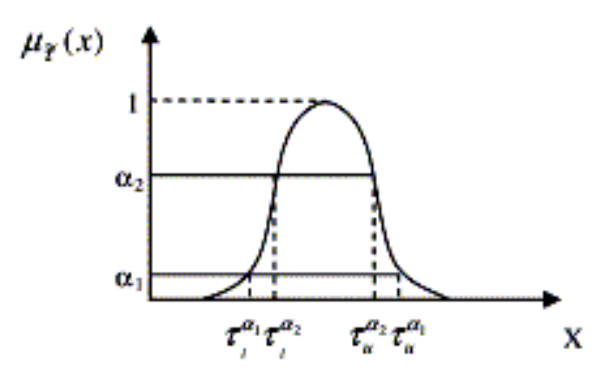

Figure 2. Fuzzy number $\tilde{\tau}$ with $\alpha$-cuts 


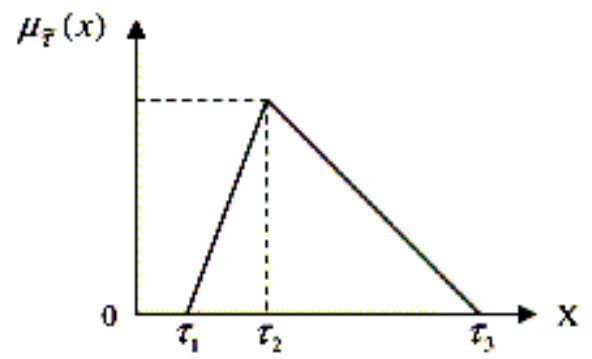

Figure 3. A triangular fuzzy numbers $\tilde{\tau}$

If $\tau$ is a fuzzy number and $\tau^{n}>0$ for $\alpha[0,1]$, then $\tau$ is called a positive fuzzy number.

Given any two positive fuzzy numbers $\not \partial, \mathfrak{t}$ and a positive real number $r$, the $\alpha$-cut of two fuzzy numbers are $\beta^{a}=\left[\beta_{i}^{\alpha}, \rho_{m}^{\alpha}\right]$, and $\tau^{a}=\left[\tau_{i}^{\alpha}, \tau_{m}^{\alpha}\right](\alpha \quad[0,1])$ respectively. According to the interval of confidence, some main operations of positive fuzzy numbers $\rho$ and $\tau$ can be expressed as follows (Kaufmann \& Gupta, 1985):

$(\tilde{\rho}(+) \tilde{\tau})^{\alpha}=\left[\rho_{l}^{\tilde{i}}+\tau_{l}^{\mathrm{u}}, \rho_{\mathrm{m}}^{\dot{\alpha}}+\tau_{m}^{\mathrm{u}}\right]$

$(\tilde{\rho}(-) \tilde{\tau})^{\alpha}=\left[\rho_{l}^{\tilde{a}}-\tau_{l}^{\tilde{a}}, \rho_{m}^{\tilde{a}}-\tau_{m}^{\tilde{a}}\right]$

$(\tilde{\rho}(.) \tau)^{\alpha}=\left[\rho^{*} \cdot \tau_{l}^{\mathrm{u}}, \rho_{m}^{\mathrm{u}} \cdot \tau_{m}^{\mathrm{u}}\right]$

$(\tilde{\rho}(:) \tilde{\mathrm{\tau}})^{\alpha}=\left[\frac{\rho \tilde{f}}{\tau \tilde{\xi}}, \frac{\rho \tilde{m}}{\tau \tilde{\tau}}\right]$

$\left(g^{\alpha}\right)^{-1}==\left[\frac{2}{p e}, \frac{1}{\rho \tilde{p}}\right]$

$(\not \partial(.) r)^{\alpha}=\left[\rho^{\alpha} \cdot r, \rho_{\mathrm{m}}^{\alpha}, r \quad\right]$ 


$$
(\widetilde{\rho}(:) r)^{\alpha}=\left[\frac{\rho \tilde{E}}{r}, \frac{\tilde{m}}{r}\right]
$$

If $\hat{t}$ is a triangular fuzzy number and $\tau_{l}^{\alpha}>0, \tau_{m}^{\alpha} \leq 1$ for $\alpha \quad[0,1]$, then $t$ is called a normalized positive triangular fuzzy number (Zimmermann, 1991).

A linguistic variable is a variable whose values are linguistic terms (Zadeh, 1975). The concept of linguistic variable is very useful in dealing with situations which are too complex or too ill-defined to be reasonably described in conventional quantitative expressions. The linguistic values can be represented by fuzzy numbers.

Let $\tilde{\rho}=\left(\rho_{1}, \rho_{2}, \rho_{3}\right)$ and $\tilde{\tau}=\left(\tau_{1}, \tau_{2}, \tau_{3}\right)$ be two triangular fuzzy numbers, then the vertex method is defined to calculate the distance between them as

$$
\mathrm{d}(\tilde{\rho}, \tilde{\tau})=\sqrt{1 / 3\left[\left(\rho_{1}-\tau_{1}\right)^{2}+\left(\rho_{z}-\tau_{z}\right)^{2}+\left(\rho_{z}-\tau_{z}\right)^{2}\right]}
$$

A modified fuzzy approach to the classical TOPSIS is proposed in this section. In this paper, the importance weights of various criteria and the ratings of qualitative criteria are considered as linguistic variables. These linguistic variables can be expressed in positive triangular fuzzy numbers.

The importance weight of each criterion can be obtained by either directly assign or indirectly using pairwise comparisons. In here, it is suggested that the decision-makers use the linguistic variables to evaluate the importance of the criteria and the ratings of alternatives with respect to various criteria. Assuming that a decision group has $\mathrm{K}$ people, the importance of the criteria and the rating of alternatives with respect to each criterion can be calculated as

$$
\tilde{x}_{i j}=\frac{1}{k}\left[x_{i l}^{1}(+) x_{i j}^{2}(+) \ldots(+) x_{i j}^{2}\right]
$$

Chen (2000) calculates the weight of each criterion by summing the assigned weights by experts and then dividing the sum by the number of experts as in Eq. (13):

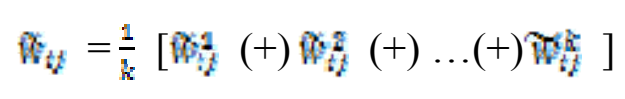

where $x$ and are the rating and the importance weight of the Kth decision maker.

A pairwise comparison matrix in the AHP method is an excellent way of determining the weights of the criteria or the alternatives. A comparison matrix divides the problem into sub-problems in a way that humans can solve these easily. Therefore, we propose modifying Chen's (2000) weighting procedure by using fuzzy comparison matrices. Chang's (1996) extent analysis will be utilized for this aim.

The stages of extent analysis approach can be summarized as follows: Letting $\mathrm{C}_{\mathrm{j}}=\left\{\mathrm{C}_{1}, \mathrm{C}_{2}, \ldots, \mathrm{C}_{\mathrm{n}}\right\}$ be a criteria set. Extent analysis values for each criterion can be 
obtained as follows: Let $\tilde{M}_{l}(\mathrm{j}=1,2,3, \ldots, \mathrm{n})$ be TFNs.

The value of fuzzy synthetic extent for the degree of possibility of $\AA_{1} \geq A_{2}$ are defined, respectively, as

$$
\mathrm{S}_{\mathrm{i}}=\sum_{j=1}^{n} M_{j} \otimes\left[\Sigma_{i=1}^{m} \Sigma_{j=1}^{m} M_{j}\right]^{-1}
$$

In our case, $\mathrm{n}=\mathrm{m}$ since a comparison matrix for criteria always has to be a square matrix.

$$
\mathrm{V}\left(\boldsymbol{H}_{1} \geq h_{\Sigma}\right)=\sup \left[\min \left(\mu_{\delta_{1}}(\mathrm{x}), \mu_{\sigma_{2}}(\mathrm{y})\right)\right]
$$

When $(\mathrm{x}, \mathrm{y})$ exists such that $\mathrm{x} \geq \mathrm{y}$ and $\mu_{\mathrm{m}}=\mu_{\mathrm{x}}=1, \mathrm{~V}\left(\tilde{M}_{1} \geq \tilde{A}_{\mathbb{2}}\right)=1$ is obtained. Since $\widetilde{M}_{1}$ and $W_{2}$ are convex fuzzy numbers, the following principle of the comparison of fuzzy numbers is applied:

$\mathrm{V}\left(\mathrm{M}_{1} \geq \mathbb{N}_{2}\right)=1$ iff $\mathrm{m}_{1} \geq \mathrm{m}_{2}$

And

$\mathrm{V}\left(\mathscr{W}_{\Omega} \geq \mathscr{W}_{1}\right)=\operatorname{hgt}\left(\mathscr{W}_{1} \cap \mathscr{A}_{\Omega}\right)=\mu(\mathrm{d})$

where $d$ is the ordinate of the highest intersection point $\mathrm{D}$ between $\mu_{N_{1}}$ and $\mu_{f_{2}}$. When $A_{1}=$ $\left(\mathrm{l}_{1}, \mathrm{~m}_{1}, \mathrm{u}_{1}\right) \quad$ and $\mathbb{\Omega}_{\mathrm{s}}=\left(\mathrm{l}_{2}, \mathrm{~m}_{2}, \mathrm{u}_{2}\right) \quad$, the following equation for the ordinate of the point $\mathrm{D}$ is given (see Fig. 4);

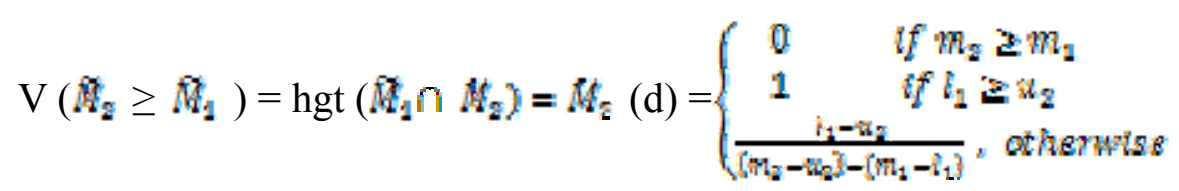

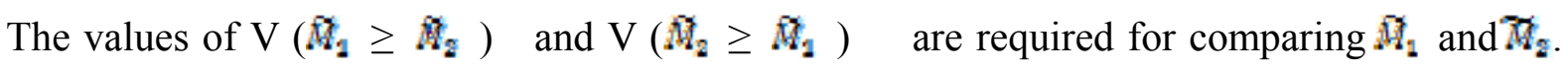
The degree of possibility for a convex fuzzy number to be greater than $\mathrm{p}$ convex fuzzy numbers $\left(\|_{j}, \frac{s}{2}=1.2 .3 \ldots, n\right) \quad$ is defined as

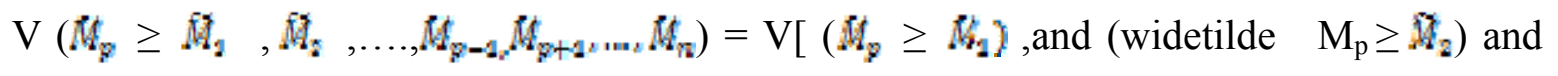




$$
\left.\left(\dot{M}_{p} \geq \vec{A}_{n}\right)\right]=\min \mathrm{V}\left(\ddot{M}_{p} \geq M_{i}\right)=\mathrm{d}\left(\mathrm{C}_{\mathrm{j}}\right), \quad \mathrm{j} \neq \mathrm{p}
$$

Consequently, the weight vector $\mathrm{W}^{\prime}=\left(\mathrm{d}^{\prime}\left(\mathrm{C}_{1}\right), \mathrm{d}^{\prime}\left(\mathrm{C}_{2}\right), \ldots, \mathrm{d}^{\prime}\left(\mathrm{C}_{\mathrm{n}}\right)\right)^{\mathrm{T}}, \mathrm{j}=1,2,3, \ldots, \mathrm{n}$ is obtained. Finally, via normalization, the following normalized weight vector is obtained:

$$
\mathrm{W}=\left(\mathrm{d}\left(\mathrm{C}_{1}\right), \mathrm{d}\left(\mathrm{C}_{2}\right), \ldots, \mathrm{d}\left(\mathrm{C}_{\mathrm{n}}\right)\right)^{\mathrm{T}} \text {. }
$$

As stated above, a fuzzy multi-criteria group decision-making problem which can be concisely expressed in matrix format as

$\widetilde{D}=\left[\begin{array}{cccc}\tilde{x}_{11} & \tilde{x}_{12} & \cdots & x_{1 n} \\ \tilde{x}_{g 1} & \cdots & \cdots & x_{g n} \\ \vdots & \vdots & 4 & \vdots \\ x_{m 1} & x_{m 2}^{*} & \cdots & x_{m n}\end{array}\right]$

where $x_{t, j} \forall \mathrm{i}, \mathrm{j}$ are linguistic variables. These linguistic variables can be described by triangular fuzzy numbers: $\tilde{x}_{i j}=\left(a_{i j}, b_{i j}, c_{i j}\right)$.

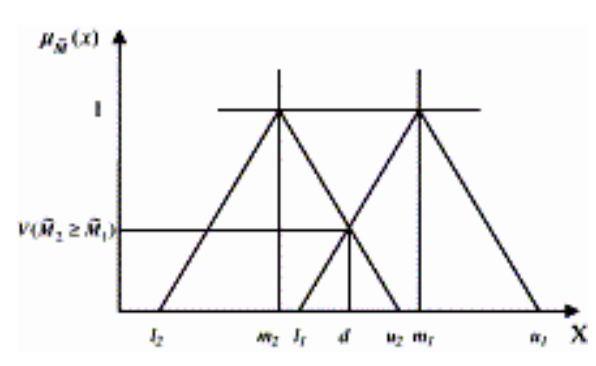

Figure 4. The intersection between $\tilde{M}_{2}$ and $\tilde{F}_{2}$.

Linear normalization will be used to transform the various criteria scales into a comparable scale because it does not need the complicated calculations of vector normalization. Therefore, we can obtain the normalized fuzzy decision matrix denoted by $\tilde{R}$.

$\widetilde{R}=\left[r_{i j}\right]_{\mathrm{m} \times \mathrm{n}}$

where $\mathrm{B}$ and $\mathrm{C}$ are the set of benefit criteria and cost criteria, respectively, and 


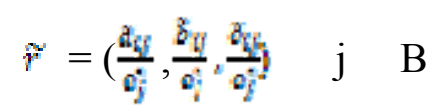

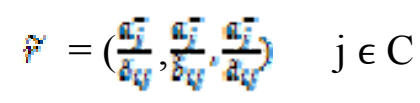

$\tilde{c}_{j}=\max c_{i j} \quad$ if $\quad \mathrm{j} \in \mathrm{B}$

$a_{j}^{-}=\min a_{i j} \quad$ If $\quad \mathrm{j} \in \mathrm{C}$

The normalization method mentioned above is to preserve the property that the ranges of normalized triangular fuzzy numbers belong to $[0,1]$.

Considering the different importance of each criterion, we can construct the weighted normalized fuzzy decision matrix as

$$
v=\left[v_{i j}\right]_{\mathrm{m} \times \mathrm{n}} \quad \mathrm{i}=1,2, \ldots, \mathrm{m} \quad \mathrm{j}=1,2, \ldots, \mathrm{n} \quad \text { where } \quad \vartheta_{i j}=r_{i j}(.) \mathrm{d}\left(\mathrm{C}_{\mathrm{j}}\right)
$$

According to the weighted normalized fuzzy decision matrix, we know that the elements $v_{t j}$

$\forall \mathrm{i}, \mathrm{j}$ are normalized positive triangular fuzzy numbers and their ranges belong to the closed interval $[0,1]$. Then, we can define the fuzzy positive-ideal solution (FPIS, A*) and fuzzy negative-ideal solution (FNIS, $\mathrm{A}^{-}$) as

$$
\begin{aligned}
& \mathrm{A}^{*}=\left(v_{1}^{*}, v_{2}^{*}, \ldots, \hat{v}_{n}^{*}\right) \\
& A^{-}=\left(v_{1}^{-}, w_{2}^{-}, \ldots, w_{n}^{-}\right)
\end{aligned}
$$

where $\tilde{v}_{j}^{*}=(1,1,1)$ and $\tilde{v}_{j}^{-}=(0,0,0) \quad, \mathrm{j}=1,2, \ldots, \mathrm{n}$.

The distance of each alternative from $\mathrm{A}^{*}$ and $\mathrm{A}-$ can be currently calculated as

$$
\begin{aligned}
& d_{\mathrm{i}}^{*}=\Sigma_{j-\mathrm{a}} d\left(v_{t,} v_{j}\right), \quad \mathrm{i}=1,2, \ldots, \mathrm{m} \\
& d_{i}^{-}=\sum_{j=4}^{m_{1}} d\left(v_{i j}^{*} v_{j}^{-}\right), \quad i=1,2, \ldots, m
\end{aligned}
$$




\section{Macrothink}

where $\mathrm{d}(0,0)$ is the distance measurement between two fuzzy numbers.

A closeness coefficient is defined to determine the ranking order of all alternatives once the $d_{i}^{*}$ and $d_{i}^{-}$of each alternative $\mathrm{A}_{\mathrm{i}}(\mathrm{i}=1,2, \ldots, \mathrm{m})$ are calculated. The closeness coefficient of each alternative is calculated as

$$
\mathrm{CC}_{\mathrm{i}}=\frac{\sigma_{i}}{\sigma_{i}+\sigma_{i}^{i}} \quad \mathrm{i}=1,2, \ldots, \mathrm{m}
$$

Obviously, an alternative $\mathrm{Ai}$ is closer to the (FPIS, $\mathrm{A}^{*}$ ) and farther from (FNIS, $\mathrm{A}^{-}$) as $\mathrm{CC}_{\mathrm{i}}$ approaches to 1 . Therefore, according to the closeness coefficient, we can determine the ranking order of all alternatives and select the best one from among a set of feasible alternatives.

To summarize the methodology, the steps of the multi-person multi-criteria decision making with a fuzzy set approach are given in the following.

Step 1: Appropriate linguistic variables for the weights of the criteria and the alternatives are chosen.

Step 2: A pairwise comparison matrix for the criteria is constructed

Step 3: Extent analysis approach is used to obtain the weights of the criteria.

Step 4: Fuzzy decision matrix and the normalized fuzzy decision matrix are constructed for the implementation of TOPSIS.

Step 5: Weighted normalized fuzzy decision matrix is constructed.

Step 6: FPIS and FNIS are determined.

Step 7: The distance of each alternative from FPIS and FNIS are calculated, respectively.

Step 8: The closeness coefficient of each alternative is calculated.

Step 9: According to the closeness coefficient, the ranking order of all alternatives can be determined.

\section{An application}

In this study, among the various criteria, the most important are used in evaluating performance. Table 1 gives the list of the evaluation criteria in this study. 
Table 1. List of evaluation criteria

\begin{tabular}{|cl|}
\hline Aspect & \multicolumn{1}{c|}{ Criteria } \\
\hline Financial & $\left(\mathrm{C}_{1}\right)$ : Reduction cost of units after the use of IT services \\
& $\left(\mathrm{C}_{2}\right)$ : Improve project implementation based on budget \\
\hline $\begin{array}{c}\text { Learning and } \\
\text { growth }\end{array}$ & $\left(\mathrm{C}_{3}\right)$ : Development of knowledge management for future \\
needs and growth of innovative activities. \\
$\left(\mathrm{C}_{4}\right)$ : Growth and empower users in the field of Information \\
Technology. \\
\hline \\
Customer & $\left(\mathrm{C}_{5}\right)$ : Maximize satisfaction of citizens \\
& $\left(\mathrm{C}_{6}\right)$ : Providing online services to citizens \\
& $\left(\mathrm{C}_{7}\right)$ : Accuracy and timeliness of information \\
\hline Internal & $\left(\mathrm{C}_{7}\right)$ : Increase efficiency of organizations in activities \\
business & $\left(\mathrm{C}_{8}\right)$ : Improve the reporting process and receive reports \\
\hline
\end{tabular}

Hierarchical structure of evaluating performance of IT department is presented in Fig. 5.

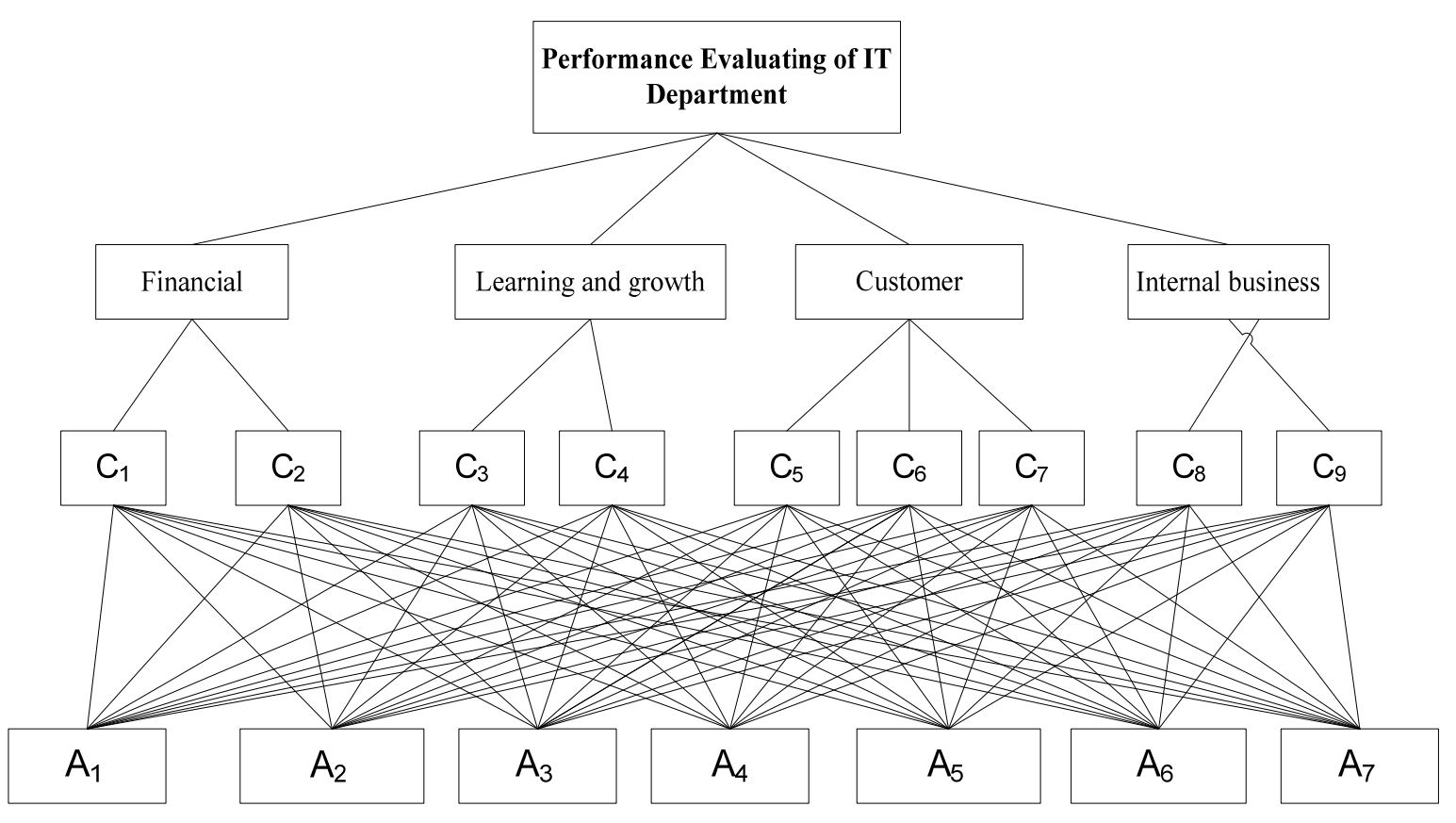

Figure 5. The hierarchical structure for the selection of best alternative 
Table 2. Fuzzy evaluation scores for the pairwise comparisons

\begin{tabular}{|ll|}
\hline Linguistic terms & Fuzzy score \\
\hline Absolutely strong (AS) & $(2,5 / 2,3)$ \\
\hline Very strong (VS) & $(3 / 2,2,5 / 2)$ \\
\hline Fairly strong (FS) & $(1,3 / 2,2)$ \\
\hline Slightly strong (SS) & $(1,1,3 / 2)$ \\
\hline Equal (E) & $(1,1,1)$ \\
\hline Slightly weak (SW) & $(2 / 3,1,1)$ \\
\hline Fairly weak (FW) & $(1 / 2,2 / 3,1)$ \\
\hline Very weak (VW) & $(2 / 5,1 / 2,2 / 3)$ \\
\hline Absolutely weak (AW) & $(1 / 3,2 / 5,1 / 2)$ \\
\hline
\end{tabular}

Table 3. Pairwise comparisons of evaluation criteria

\begin{tabular}{|cccccccccc|}
\hline & $\mathbf{C}_{1}$ & $\mathbf{C}_{2}$ & $\mathbf{C}_{3}$ & $\mathbf{C}_{\mathbf{4}}$ & $\mathbf{C}_{5}$ & $\mathbf{C}_{\mathbf{6}}$ & $\mathbf{C}_{\mathbf{7}}$ & $\mathbf{C}_{\mathbf{8}}$ & $\mathbf{C}_{9}$ \\
\hline $\mathbf{C}_{\mathbf{1}}$ & $(1,1,1)$ & $(1,1,1.5)$ & $(.4, .5, .67)$ & $\ldots$ & $\ldots$ & $\ldots$ & $\ldots$ & $\ldots$ & $(1.5,2,2.5)$ \\
\hline $\mathbf{C}_{\mathbf{2}}$ & $(.67,1,1)$ & $(1,1,1)$ & $(.33, .40, .50)$ & $\ldots$ & $\ldots$ & $\ldots$ & $\ldots$ & $\ldots$ & $(.67,1,1)$ \\
\hline $\mathbf{C}_{3}$ & $(1.5,2,2.5)$ & $(2,2.5,3)$ & $(1,1,1)$ & $\ldots$ & $\ldots$ & $\ldots$ & $\ldots$ & $\ldots$ & $(2,2.5,3)$ \\
\hline $\mathbf{C}_{4}$ & $(.4, .5, .67)$ & $(1.5,2,2.5)$ & $(.67,1,1)$ & $\ldots$ & $\ldots$ & $\ldots$ & $\ldots$ & $\ldots$ & $(.5, .67,1)$ \\
\hline $\mathbf{C}_{5}$ & $(1,1,1.5)$ & $(.67,1,1)$ & $(.40, .50, .67)$ & $\ldots$ & $\ldots$ & $\ldots$ & $\ldots$ & $\ldots$ & $(1,1.5,2)$ \\
\hline $\mathbf{C}_{\mathbf{6}}$ & $(.4, .5, .67)$ & $(1, .5, .67)$ & $(.33, .40, .50)$ & $\ldots$ & $\ldots$ & $\ldots$ & $\ldots$ & $\ldots$ & $(.33,40, .50)$ \\
\hline $\mathbf{C}_{7}$ & $(.33, .4, .5)$ & $(.67,1,1)$ & $(1,1.5,2)$ & $\ldots$ & $\ldots$ & $\ldots$ & $\ldots$ & $\ldots$ & $(1,1,1.5)$ \\
\hline $\mathbf{C}_{8}$ & $(1,1,1.5)$ & $(.5, .67,1)$ & $(1.5,2,2.5)$ & $\ldots$ & $\ldots$ & $\ldots$ & $\ldots$ & $\ldots$ & $(.33, .40, .50)$ \\
\hline $\mathbf{C}_{9}$ & $(.4, .5, .67)$ & $(1,1,1.5)$ & $(.33, .40,2)$ & $\ldots$ & $\ldots$ & $\ldots$ & $\ldots$ & $\ldots$ & $(1,1,1)$ \\
\hline
\end{tabular}

In the next step, using Eq. (15) fuzzy synthetic extent values $\left(\mathrm{S}_{\mathrm{j}}\right)$ for the evaluation criteria are produced. After obtaining the synthetic extent values, Eqs. (16), (17), (18), (19) and (20) are used for calculating the weight vector. Finally, via normalization, normalized weight vector is obtained as in Table 4.

Table 4. Results of the fuzzy AHP procedure for the determination of the weights

\begin{tabular}{|c|c|c|c|}
\hline & $s_{1}=h_{1}=\left(\mathbf{l}_{j}, \mathbf{m}_{\mathrm{j}}, \mathbf{u}_{\mathbf{j}}\right)$ & $w_{j}=d\left(\mathbf{C}_{\mathbf{j}}\right)^{\mathrm{T}}$ & $\mathbf{W}_{\mathbf{j}}=\mathbf{d}\left(\mathrm{C}_{\mathbf{j}}\right)^{\mathbf{T}}$ \\
\hline $\mathrm{C}_{1}$ & $(.09, .13, .20)$ & 0.938 & 0.108 \\
\hline $\mathrm{C}_{2}$ & $(.06, .09, .15)$ & 0.976 & 0.112 \\
\hline $\mathrm{C}_{3}$ & $(.10, .15, .23)$ & 0.921 & 0.106 \\
\hline $\mathrm{C}_{4}$ & $(.06, .09, .15)$ & 0.977 & 0.112 \\
\hline $\mathrm{C}_{5}$ & $(.08, .12, .18)$ & 0.954 & 0.109 \\
\hline $\mathrm{C}_{6}$ & $(.05, .07, .10)$ & 1 & 0.115 \\
\hline $\mathrm{C}_{7}$ & $(.06, .09, .15)$ & 0.981 & 0.113 \\
\hline $\mathrm{C}_{8}$ & $(.07, .10, .15)$ & 0.975 & 0.112 \\
\hline $\mathrm{C}_{9}$ & $(.07, .11, .19)$ & 0.959 & 0.110 \\
\hline
\end{tabular}




\section{Macrothink Institute ${ }^{\mathrm{TM}}$}

Next step is the determination of the best alternative with the proposed fuzzy TOPSIS procedure. To do this, three experts evaluated alternatives with respect to each criterion using Table 5. While the experts evaluate the alternatives, they assume that all the criteria are benefit criteria.

Table 5.Fuzzy evaluation scores for the alternatives

\begin{tabular}{|cc|}
\hline Linguistic terms & Fuzzy score \\
\hline Very poor (VP) & $(0,0,1)$ \\
\hline Poor (P) & $(0,1,3)$ \\
\hline Medium poor (MP) & $(1,3,5)$ \\
\hline Fair (F) & $(3,5,7)$ \\
\hline Medium good (MG) & $(5,7,9)$ \\
\hline Good (G) & $(7,9,10)$ \\
\hline Very good (VG) & $(9,10,10)$ \\
\hline
\end{tabular}

After forming decision matrix, Eqs. (24), (25), (26) and (27) are used to produce fuzzy normalized evaluation matrix (see Table 6). Following this step, the weighted normalized fuzzy decision matrix (see Table 7) is constructed utilizing Eq. (28).

Table 6. Fuzzy normalized evaluation matrix for the alternatives

\begin{tabular}{|ccccccccccc|}
\hline & $\mathbf{C}_{1}$ & $\mathbf{C}_{2}$ & $\mathbf{C}_{3}$ & $\mathbf{C}_{\mathbf{4}}$ & $\mathbf{C}_{5}$ & $\mathbf{C}_{6}$ & $\mathbf{C}_{7}$ & $\mathbf{C}_{\mathbf{8}}$ & $\mathbf{C}_{\mathbf{9}}$ \\
\hline $\mathbf{A}_{\mathbf{1}}$ & $(.48, .59, .67)$ & $(.90,1.0,1.0)$ & $(.44, .56, .69)$ & $(.35, .39, .46)$ & $\ldots$ & $\ldots$ & $\ldots$ & $\ldots$ & $(.46, .58, .60)$ \\
\hline $\mathbf{A}_{\mathbf{2}}$ & $(.23, .31, .39)$ & $(.56, .60, .64)$ & $(.75, .81, .87)$ & $(.57, .59, .64)$ & $\ldots$ & $\ldots$ & $\ldots$ & $\ldots$ & $(.36, .39, .43)$ \\
\hline $\mathbf{A}_{3}$ & $(.23, .36, .39)$ & $(.36, .39, .43)$ & $(.80, .90,1.0)$ & $(.23, .36, .39)$ & $\ldots$ & $\ldots$ & $\ldots$ & $\ldots$ & $(.20, .30, .40)$ \\
\hline $\mathbf{A}_{4}$ & $(.36, .39, .43)$ & $(.46, .58, .60)$ & $(.67, .69, .73)$ & $(.23, .36, .39)$ & $\ldots$ & $\ldots$ & $\ldots$ & $\ldots$ & $(.75, .81, .87)$ \\
\hline $\mathbf{A}_{5}$ & $(.48, .59, .67)$ & $(.23, .36, .39)$ & $(.56, .60, .64)$ & $(.67, .69, .73)$ & $\ldots$ & $\ldots$ & $\ldots$ & $\ldots$ & $(.67, .69, .73)$ \\
\hline $\mathbf{A}_{6}$ & $(.35, .39, .46)$ & $(.23, .36, .39)$ & $(.35, .39, .46)$ & $(.35, .39, .46)$ & $\ldots$ & $\ldots$ & $\ldots$ & $\ldots$ & $(.75, .81, .87)$ \\
\hline $\mathbf{A}_{7}$ & $(.46, .58, .60)$ & $(.23, .31, .39)$ & $(.48, .59, .67)$ & $(.20, .30, .40)$ & $\ldots$ & $\ldots$ & $\ldots$ & $\ldots$ & $(.35, .39, .46)$ \\
\hline
\end{tabular}

Table 7.Fuzzy weighted decision matrix

\begin{tabular}{|cccccccccc|}
\hline & $\mathbf{C}_{\mathbf{1}}$ & $\mathbf{C}_{2}$ & $\mathbf{C}_{3}$ & $\mathbf{C}_{5}$ & $\mathbf{C}_{6}$ & $\mathbf{C}_{7}$ & $\mathbf{C}_{8}$ & $\mathbf{C}_{9}$ \\
\hline $\mathbf{A}_{\mathbf{1}}$ & $(.051, .063, .072)$ & $(.101, .112, .112)$ & $(.046, .059, .073)$ & $\ldots$ & $\ldots$ & $\ldots$ & $\ldots$ & $(.050, .064, .066)$ \\
\hline $\mathbf{A}_{\mathbf{2}}$ & $(.024, .033, .042)$ & $(.062, .067, .071)$ & $(.079, .085, .092)$ & $\ldots$ & $\ldots$ & $\ldots$ & $\ldots$ & $(.039, .043, .047)$ \\
\hline $\mathbf{A}_{3}$ & $(.024, .038, .042)$ & $(.040, .043, .048)$ & $(.084, .095, .106)$ & $\ldots$ & $\ldots$ & $\ldots$ & $\ldots$ & $(.022, .033, .044)$ \\
\hline $\mathbf{A}_{4}$ & $(.038, .042, .046)$ & $(.051, .065, .067)$ & $(.071, .073, .077)$ & $\ldots$ & $\ldots$ & $\ldots$ & $\ldots$ & $(.082, .089, .096)$ \\
\hline $\mathbf{A}_{5}$ & $(.051, .063, .072)$ & $(.025, .040, .043)$ & $(.059, .063, .067)$ & $\ldots$ & $\ldots$ & $\ldots$ & $\ldots$ & $(.074, .076, .080)$ \\
\hline $\mathbf{A}_{6}$ & $(.037, .042, .049)$ & $(.025, .040, .043)$ & $(.037, .041, .048)$ & $\ldots$ & $\ldots$ & $\ldots$ & $\ldots$ & $(.082, .089, .096)$ \\
\hline $\mathbf{A}_{7}$ & $(.049, .062, .064)$ & $(.025, .034, .043)$ & $(.050, .062, .071)$ & $\ldots$ & $\ldots$ & $\ldots$ & $\ldots$ & $(.038, .043, .050)$ \\
\hline
\end{tabular}

After obtaining the fuzzy weighted decision table, Eqs. (29), (30), (31) and (32) are used to calculate the distance of each alternative from the positive ideal (FPIS, $\mathrm{A}^{*}$ ) and negative ideal 
(FNIS, A-) solutions. Finally, Eq. (33) is used for calculating the closeness coefficient $\left(\mathrm{CC}_{\mathrm{i}}\right)$ of each alternative.

The results of the modified fuzzy TOPSIS analysis are summarized in Table 8. Based on $\mathrm{CC}_{\mathrm{i}}$ values, the ranking of the alternatives in descending order are $A_{1}, A_{4}, A_{5}, A_{7}, A_{7}, A_{6}, A_{3}$ and $\mathrm{A}_{2}$. According to the last step, the best alternative is $\mathrm{A}_{1}$.

Table 8.Fuzzy modified TOPSIS results

\begin{tabular}{|cccc|}
\hline & $d_{i}^{-}$ & $d_{i}^{*}$ & $\mathbf{C C}_{\mathbf{i}}$ \\
\hline $\mathbf{A}_{\mathbf{1}}$ & 0.015 & 0.005 & 0.723 \\
\hline $\mathbf{A}_{\mathbf{2}}$ & 0.003 & 0.019 & 0.153 \\
\hline $\mathbf{A}_{\mathbf{3}}$ & 0.005 & 0.018 & 0.217 \\
\hline $\mathbf{A}_{\mathbf{4}}$ & 0.011 & 0.009 & 0.555 \\
\hline $\mathbf{A}_{\mathbf{5}}$ & 0.010 & 0.013 & 0.431 \\
\hline $\mathbf{A}_{\mathbf{6}}$ & 0.006 & 0.018 & 0.247 \\
\hline $\mathbf{A}_{\mathbf{7}}$ & 0.005 & 0.014 & 0.278 \\
\hline
\end{tabular}

\section{Conclusions}

This paper proposes an approach based on the Fuzzy TOPSIS and BSC for evaluating the performance of IT department in Tehran Province Gas Company. The analytic hierarchy is structured by the four major perspectives of the BSC including financial, customer, internal business process, and learning and growth, followed by performance indicators. Because human decision-making process usually contains fuzziness and vagueness, the Fuzzy TOPSIS is adopted to solve the problem. The results show that $A_{1}$ is the best alternative among other alternatives.

Some distinguished contributions of this research are as follows:

1. This research adopts the concept of the BSC to develop a performance evaluation structure for IT department in Tehran Province Gas Company. Based on literature review and interview with experts in IT field, we finalize with nine most important performance indicators for IT departments. These indicators can be a reference for IT departments in performance evaluation.

2. This research bases on the fuzzy set theory and the TOPSIS to propose a systematic performance evaluation model to provide guidance to IT department managers regarding performance evaluation and strategies for improving department performance.

3. A Fuzzy TOPSIS IS is constructed to assist the calculation of appropriate weightings for performance evaluation in IT department. An IT department can adopt this IS for routine performance evaluation of the department. On top of that, this IS is very user-friendly and can also be used for solving general MCDM problems with fuzzy nature in real practice and 
in research. Coding knowledge is not required for using this IS. The user only needs some basic knowledge of conventional TOPSIS to construct the hierarchy and input the questionnaire and the results can be obtained by clicking the icons. On the other hand, the IS can be easily altered by modifying the logic behind to adopt different Fuzzy TOPSIS models for research purposes.

\section{References}

Amg,L.,Wen,C \& Ching, J.(2008).A fuzzy AHP and BSC approach for evaluating performance of IT department in the manufacturing industry in Taiwan, Expert systems with Applications 34, 94-107

Abran and Buglione, A. Abran and L. Buglione. (2003). A multidimensional performance model for consolidating balanced scorecards, Advances in Engineering Software 34, pp. 339-349.

Banker et al., R.D. Banker, H. Chang, S.N. Janakiraman and C. Konstans. (2004). A balanced scorecard analysis of performance metrics, European Journal of Operational Research 154, pp. $423-436$.

Chang, D.Y. Chang.(1996). Applications of the extent analysis method on fuzzy AHP, European Journal of Operational Research 95, pp. 649-655.

Chen, C. Chen. (2000). Extensions of the TOPSIS for group decision-making under fuzzy environment, Fuzzy Sets and Systems 114, pp. 1-9

Hafeez et al., K. Hafeez, Y. Zhang and N. Malak. (2002). Determining key capabilities of a firm using analytic hierarchy process, International Journal of Production Economics 76, pp. $39-51$.

Kaplan and Norton, R.S. Kaplan and D.P. Norton. (1992). The balanced scorecard: measures that drive performance, Harvard Business Review 70 (1), pp. 71-79.

Kaplan and Norton, R.S. Kaplan and D.P. Norton. (1993). Putting the balanced scorecard to work, Harvard Business Review 71 (5), pp. 134-142.

Kaplan and Norton, R.S. Kaplan and D.P. Norton. (1996). Using the balanced scorecard as a strategic management system, Harvard Business Review 74 (1), pp. 75-85.

Kaplan and Norton, R.S. Kaplan and D.P. Norton. (1996). The balanced scorecard: translating strategy into action, Harvard Business School Press, Boston.

Hill, T., Westbrook, R. (1997). "SWOT analysis: it's time for a product recall", Long Range Planning, 30, 46-52.

Kaufmann and Gupta, A. Kaufmann and M.M. Gupta. (1985). Introduction to fuzzy arithmetic: Theory and applications, Van Nostrand Reinhold, New York. 


\section{Macrothink}

Martinsons, Martinsons, M.G. (1992). Strategic thinking about information management, Keynote Address to the 11th annual conference of the International Association of Management Consultants, Toronto.

Martinsons et al., M. Martinsons, R. Davison and D. Tse. (1999). The balanced scorecard: a foundation for the strategic management of information systems, Decision Support Systems 25 , pp. 71-88.

Milis and Mercken, K. Milis and R. Mercken (2004). The use of the balanced scorecard for the evaluation of information and communication technology projects, International Journal of Project Management 22, pp. 87-97.

Ravi et al., V. Ravi, R. Shankar and M.K. Tiwari. (2005). Analyzing alternatives in reverse logistics for end-of-life computers: ANP and balanced scorecard approach, Computers and Industrial Engineering 48, pp. 327-356.

Willcocks and Lester, L. Willcocks and S. Lester. (1994). evaluating the feasibility of information systems investments: recent UK evidence and new approaches. In: L. Willcocks, Editor, Information management: the evaluation of information systems investments, Chapman \& Hall, London.

Yong, D. Yong. (2006). Plant location selection based on fuzzy TOPSIS, International Journal of Advanced Manufacturing Technologies 28, pp. 839-844.

Zadeh, L. A. (1975). The concept of a linguistic variable and its application to approximate reasoning. Information Sciences 8, 199-249 (I), 301-357 (II).

Zimmermann, H.J. (1991). Fuzzy set theory and its applications (2nd ed.), Kluwer Academic Publishers, Boston, Dordrech, London. 